\title{
Malignant hypertension: cardiac structure and function at presentation and during therapy
}

\author{
L M SHAPIRO, D G BEEVERS \\ From the University of Birmingham, Department of Medicine, Dudley Road Hospital, Birmingham
}

SUMMARY We have studied electrocardiograms, chest radiographs, and digitised apex echocardiograms in 16 patients with malignant hypertension before and after up to six months of antihypertensive treatment and compared them with those of eight patients with severe benign hypertension.

Adequate blood pressure reduction was obtained in 14 with resolution of retinopathy, but one patient died and another had poor blood pressure control. Nine had electrocardiographic criteria of left ventricular hypertrophy which did not change with treatment and 10 had lateral ischaemia which resolved in seven.

The malignant hypertensives were divided into seven with and nine without a previous hypertensive history. Both groups had normal echocardiographic cavity dimensions, but the former group tended to have hypertrophy (similar to that in benign hypertensives) and the latter did not. After adequate reduction of blood pressure, no change in wall and septal thickness occurred (except in one patient with poor blood pressure control).

At entry, malignant hypertensives showed delayed mitral valve opening with significant cavity dimension increase during prolonged isovolumic relaxation, reduced peak rate, and prolonged duration of cavity dimension increase and cavity shape change (inward wall motion) during the upstroke of the apexcardiogram which showed a tall "a" wave. After reduction of blood pressure, though the delay in mitral valve opening persisted, the timing of $A$ returned towards normal and the dimension change during the upstroke of the apexcardiogram and the relative height of the "a" wave were reduced but remained significantly different from normal.

Some patients without a previous hypertensive history may develop a malignant phase without left ventricular hypertrophy on the electrocardiogram or echocardiogram. They maintain their pump function even with radiological pulmonary oedema, have incoordinate relaxation and contraction, and have abnormal filling. Similar functional abnormalities were found in malignant hypertensives with hypertrophy. Treatment to reduce blood pressure reduces incoordinate contraction, but impaired diastolic function persists as in benign hypertension, suggesting that these abnormalities are the result of altered myocardial properties that may occur without hypertrophy.

Malignant hypertension is a rare disorder with a high but declining mortality and morbidity from renal, cerebral, and cardiac complications. ${ }^{12}$

Echocardiographic features in non-malignant hypertension may include left ventricular wall thickening, even with a normal electrocardiogram. ${ }^{3}$ This degree of hypertrophy is probably related to the severity of hypertension and is reduced by successful blood pressure control. ${ }^{45} \mathrm{We}$ have previously shown that in

Accepted for publication 27 October 1982 some untreated patients with malignant hypertension, left ventricular wall thickness, cavity dimensions, and systolic function are normal, while diastolic function is disturbed. ${ }^{\circ 7}$ We concluded that in some patients, the malignant phase is of relatively rapid onset and not preceded by prolonged hypertension which would result in hypertrophy. The purpose of the present study is to extend the previous investigation and study 16 malignant hypertensives by echocardiography before and after six months of treatment with antihypertensives. 


\section{Patients and methods}

Four groups of patients were studied.

(a) Normal: twelve normal subjects (two women, 10 men) aged 29 to 59 , mean age 42 years. All had a diastolic blood pressure (Vth phase) below $85 \mathrm{mmHg}$.

(b) Hypertensive: all were untreated before presentation to hospital. The malignant phase of hypertension was diagnosed by the presence of grade III or IV hypertensive retinopathy, that is retinal exudates and haemorrhages with or without papilloedema. All patients were initially treated with $100 \mathrm{mg}$ oral atenolol to ensure controlled blood pressure reduction. ${ }^{8}$ Echocardiography was performed within 24 hours of starting treatment when blood pressure had fallen on average $10 \%$ from the peak values. After the initial phase of therapy patients were treated with various drug combinations, including beta adrenergic blocking agents, diuretics, and vasodilators including hydralazine, minoxidil, and methyldopa. The subgroups of patients with hypertension were as follows.

(i) Severe benign hypertension: eight patients (three women, five men) aged 26 to 43 , mean age 37 years. Blood pressure at presentation ranged from $180 / 125$ to $240 /$ $155 \mathrm{mmHg}$ (mean 195/130 $\mathrm{mmHg}$ ).

(ii) Malignant hypertension: seven patients (two women, five men) with a previous history of hypertension (Table 1).

(iii) Malignant hypertension: nine patients (one woman, eight men) with no previous history of hypertension (Table 1).

\section{ELEC I ROCARDIOGRAPHY}

A standard 12 lead electrocardiogram was recorded at presentation and at intervals during treatment and the sum of the deflections of the S wave in lead V1 plus the maximum $R$ wave in V5 or V6 was noted. Left ventricular hypertrophy was assumed if this figure exceeded $3.5 \mathrm{~cm}$. The presence of ST-T changes was also noted. No subject had electrocardiographic evidence of a myocardial infarction.

\section{CHEST RADIOGRAPHY}

A standard 2 metre posteroanterior chest radiograph was taken at presentation and at intervals during treatment. The cardiothoracic ratio was determined by dividing the cardiac transverse diameter by the internal thoracic diameter, expressed as a percentage; cardiomegaly was assumed if this exceeded $50 \%$. Pulmonary oedema was recorded when Kerley's " $B$ " lines, or interstitial or alveolar oedema were present.

ESTIMATION OF LEFT VENTRICULAR DIMENSIONS AND FUNCTION

Patients were studied before or within 24 hours of starting antihypertensive treatment and at intervals during treatment. Echophonocardiography with simultaneous apexcardiogram and electrocardiogram (standard lead II) was performed in the partial left lateral position with an SK20 ultrasonoscope and a Cambridge multichannel photographic recorder with a paper speed of $10 \mathrm{~cm} / \mathrm{s}$. A left ventricular echocardiogram at the level of the tips of the mitral valve (to define onset of opening), showing clear continuous echoes from both the septum and posterior wall, was used for further analysis. The thicknesses of the $\vec{\nabla}$ interventricular septum and posterior wall were

Table 1 Clinical features, electrocardiogram, and chest radiograph in hypertensives (number with abnormal feature)

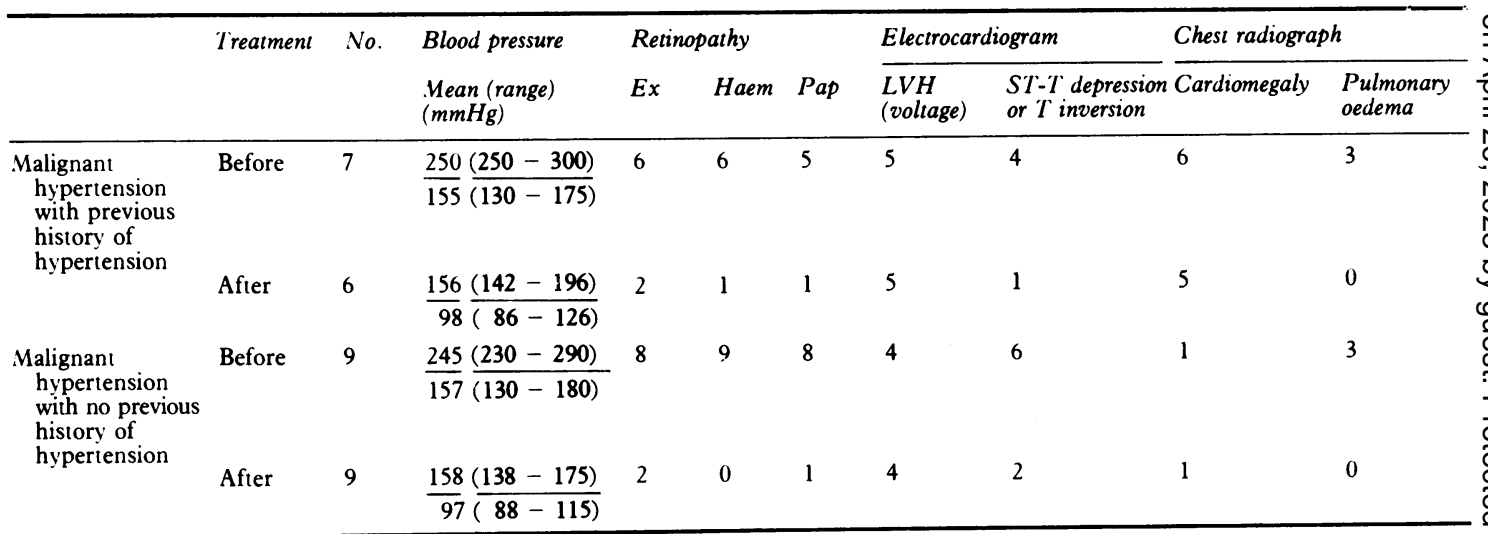

Ex, exudates; Haem, haemorrhages; Pap, papilloedema; LVH, left ventricular hypertrophy (see methods); Cardiomegaly, cardiothoracic ratio greater than $50 \%$. 
measured at end-diastole ( $R$ wave on the electrocardiogram) in $\mathrm{cm}$. Left atrial dimension was measured in $\mathrm{cm}$ at end-systole from the anterior border of the posterior atrial wall to the posterior aortic wall and expressed as a ratio of aortic root dimension.

Echocardiograms were digitised as previously described by Gibson and Brown, ${ }^{9}$ using a Summagraphics digitiser and a Prime 300 computer system. From these records the following measurements were made: (i) end-systolic cavity dimension (cm); (ii) end-diastolic cavity dimension (cm); (iii) peak rate of increase in dimension during early diastole $(\mathrm{cm} / \mathrm{s})$; (iv) early diastolic filling period, defined as the period from minimal left ventricular dimension to the time of reduction in filling to $20 \%$ of its peak value (ms); (v) time intervals in ms from the $Q$ wave of the electrocardiogram to the aortic second heart sound $\left(A_{2}\right)$ (this was corrected for heart rate as described by Weissler et al. ${ }^{10}$ and expressed as $\mathrm{QA}_{2}$ index); time from $A_{2}$ to minimum dimension, which was taken as negative if minimum dimension followed and positive if it preceded $\mathrm{A}_{2}$; time from minimum dimension to mitral valve opening; (vi) change in dimension during isovolumic relaxation expressed as a percentage of the total dimension change during the cardiac cycle; (vii) change in left ventricular dimension during the time of inscription of the upstroke of the apexcardiogram (isovolumic contraction), expressed as a percentage of the total dimension change during the cardiac cycle. ${ }^{11}$

The ratio of the apexcardiogram " $a$ " wave to the total deflection $(\mathrm{H})$ was calculated and was assumed to be raised if the $\mathrm{a} / \mathrm{H}$ ratio exceeded 0.15 (2 standard deviation from normal). ${ }^{12}$
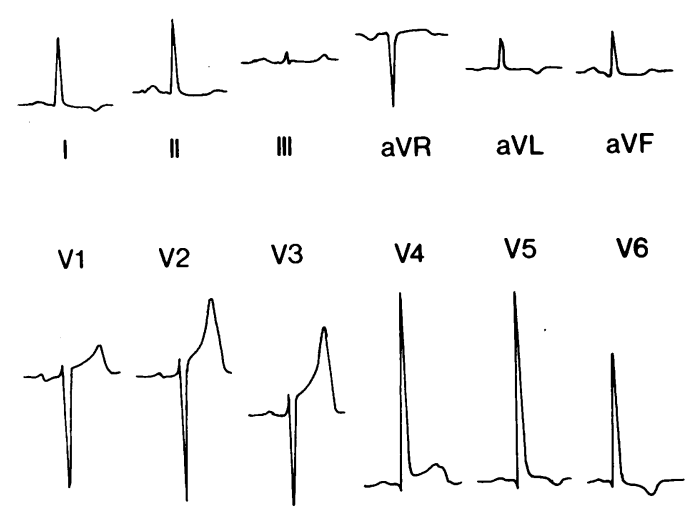

Fig. 1 Electrocardiogram of a man with malignant hypertension (previous four year history of benign essential hypertension) showing severe left ventricular hypertrophy.
STATISTICAL METHOD

Values are quoted as mean \pm one standard deviation. Student's $t$ test was used to test differences between normally distributed variables and $\chi^{2}$ between variables with a skewed distribution.

\section{Results}

CLINICAL (Table 1)

The mean blood pressure before treatment was 250/ 155 and $245 / 157 \mathrm{mmHg}$, respectively, in patients with and without a previous history of hypertension, and fell during treatment to means of 156/98 and 158/ $97 \mathrm{mmHg}$, respectively. One patient with an apparently good reduction in blood pressure (last record $166 / 95 \mathrm{mmHg}$ ) died from a stroke three weeks after presentation. Ten patients had satisfactory reductions in blood pressure (below 145/100 $\mathrm{mmHg}$ ), four had moderate reductions in blood pressure (below 165/ $115 \mathrm{mmHg}$ ), and one man with no previous hypertensive history remained severely hypertensive (196/ $125 \mathrm{mmHg}$ ) after five months, possibly because of poor compliance. Blood pressure reduction resulted in a regression of retinopathy in all but this last patient.

ELECTROCARDIOGRAPHY (Table 1; Fig. 1 and 2)

The voltage criteria for left ventricular hypertrophy were present in nine of 16 patients with malignant hypertension and all patients with benign hypertension. Lateral ST-T changes were present in 10 of 16 patients. There were wide variations, however, in the electrocardiogram at presentation from severe left ventricular hypertrophy (Fig. 1) to normal (Fig. 2). After treatment improvement in the ST-T changes was noted in some patients, suggesting resolution of subendocardial ischaemia. There was little change in electrocardiographic voltage criteria.

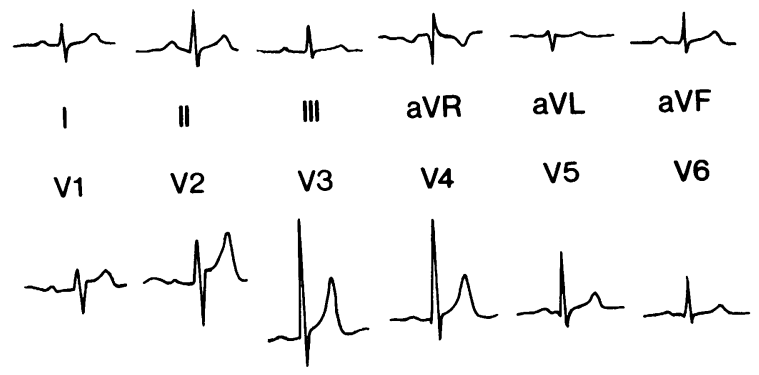

Fig. 2 Normal electrocardiogram from woman with malignant hypertension and no previous hypertensive history. 


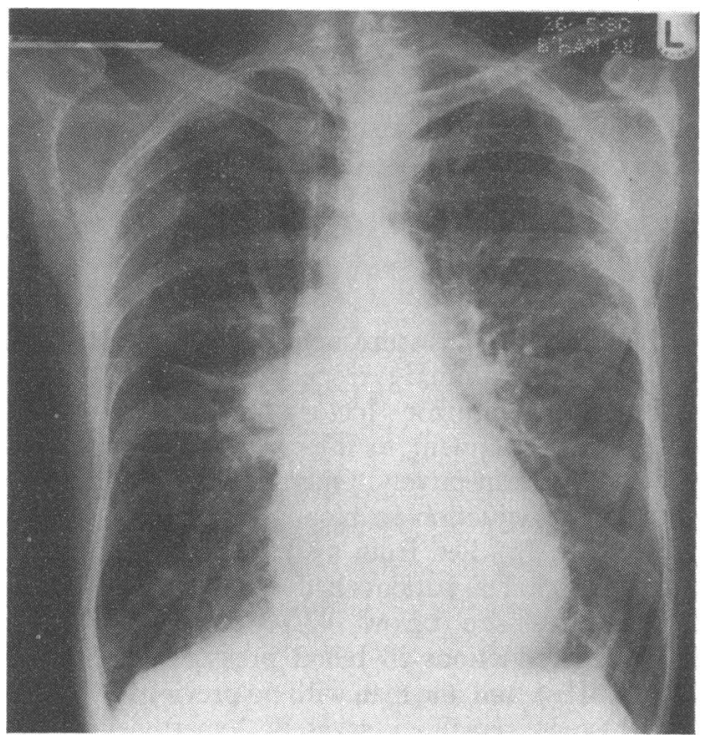

Fig. 3 Chest radiograph of man with malignant hypertension with a previous hypertensive history before treatment showing pulmonary oedema and increased heart size.

CHEST RADIOGRAPHY (Table 1, Fig. 3 and 4) Before treatment the mean cardiothoracic ratio was $57 \%$ and $47 \%$, respectively, in the malignant hypertensives with and without a previous history. Pulmonary oedema was present in six of 16 (two interstitial, two alveolar, and two with Kerley's " $B$ " lines), and in addition a further two patients had pulmonary vascular redistribution to the upper lobe vessels. There was rapid improvement in the features of pulmonary oedema in all patients with treatment but little change in heart size.

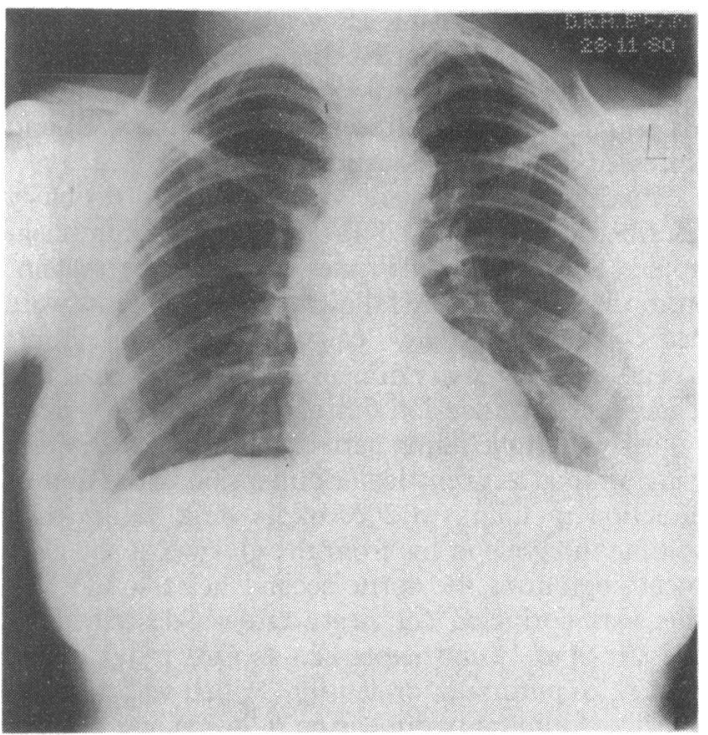

Fig. 4 Chest radiograph of malignant hypertensives without a previous history showing normal findings.

LEFT VENTRICULAR STRUCTURE (Table 2)

The mean values for cavity dimensions were normal at presentation ${ }^{6}$ and no significant change occurred with treatment. Therefore, derived indices of ejection such as fractional shortening and ejection fraction were normal and are not quoted.

The wall and septal thicknesses at presentation and during treatment are shown (Fig. 5 and 6). Those with a previous history of hypertension (Fig. 7) tended to have left ventricular hypertrophy and those without a previous history did not (Fig. 8). After

Table 2 Changes in left ventricular function in hypertensives during treatment

\begin{tabular}{|c|c|c|c|c|c|c|c|c|c|c|c|}
\hline & \multirow[t]{2}{*}{ No. } & \multirow[t]{2}{*}{ Treatment } & \multirow[t]{2}{*}{$\underset{(m s)^{2}}{Q A_{1} \text { index }}$} & \multirow{2}{*}{$\begin{array}{l}A_{2} \text { to } \\
\text { minimum } \\
\text { dimension } \\
(m s)\end{array}$} & \multirow{2}{*}{$\begin{array}{l}\text { Minimum } \\
\text { dimension } \\
\text { to } M V O \\
(m s)\end{array}$} & \multicolumn{2}{|c|}{$\begin{array}{l}\text { Increase in cavity } \\
\text { dimension }\end{array}$} & \multicolumn{2}{|c|}{$\begin{array}{l}\text { Dimension changes } \\
\% \text { of total }\end{array}$} & \multirow{2}{*}{\multicolumn{2}{|c|}{$\begin{array}{l}\text { Apexcardio- Left atrial } \\
\text { gram a/H to aortic } \\
\text { ratio } \\
\end{array}$}} \\
\hline & & & & & & $\begin{array}{l}\text { Peak rate } \\
(\mathrm{cm} / \mathrm{s})\end{array}$ & $\begin{array}{l}\text { Duration } \\
\text { (ms) }\end{array}$ & $\begin{array}{l}\text { During } \\
\text { isovolumic } \\
\text { relaxation }\end{array}$ & $\begin{array}{l}\text { During } \\
\text { upstroke } \\
\text { apexcardio- } \\
\text { gram }\end{array}$ & & \\
\hline Normal & 12 & & $540 \pm 17$ & $-46 \pm 14$ & $10 \pm 3$ & $19 \pm 3$ & $166 \pm 40$ & $0 \pm 3$ & $3 \pm 3$ & $0.07 \pm 0.04$ & $1.0 \pm 0.2$ \\
\hline $\begin{array}{l}\text { Benign hyper- } \\
\text { tension }\end{array}$ & $\begin{array}{l}8 \\
8\end{array}$ & $\begin{array}{l}\text { Before } \\
\text { After }\end{array}$ & $\begin{array}{l}542 \pm 20 \\
541 \pm 19\end{array}$ & $\begin{array}{l}-27 \pm 35 \\
-30 \pm 32\end{array}$ & $\begin{array}{l}70 \pm 15 \\
71 \pm 16\end{array}$ & $\begin{array}{l}12 \pm 3 * \\
11 \pm 7 \S\end{array}$ & $\begin{array}{l}196 \pm 30 \\
182 \pm 36\end{array}$ & $\begin{array}{l}15 \pm 7 \\
12 \pm 6\end{array}$ & $\begin{array}{l}7 \pm 4 \\
4 \pm 7\end{array}$ & $\begin{array}{l}0.12 \pm 0.06 \\
0.09 \pm 0.05\end{array}$ & $\begin{array}{l}1.2 \pm 0.5 \\
1.2 \pm 0.3\end{array}$ \\
\hline $\begin{array}{l}\text { Malignant } \\
\text { hypertension } \\
\text { with previous } \\
\text { history }\end{array}$ & $\begin{array}{l}7 \\
6 \\
6\end{array}$ & Before & $533 \pm 34$ & $\begin{array}{l}-9 \pm 45 \\
-21 \pm 40\end{array}$ & $76 \pm 18$ & $11 \pm 2 \star$ & $191 \pm 35$ & $20 \pm 11$ & $19 \pm 15 \pi$ & $0.36 \pm 0.16 \neq$ & $\ddagger 1.2 \pm 0.4$ \\
\hline $\begin{array}{l}\text { Malignant } \\
\text { hypertension } \\
\text { with no } \\
\text { previous } \\
\text { history }\end{array}$ & $\begin{array}{l}9 \\
9\end{array}$ & Before & $505 \pm 309$ & $-87 \pm 27 \ddagger$ & $71 \pm 23$ & $9 \pm 3^{\star}$ & $220 \pm 43 \pi$ & $16 \pm 15$ & $27 \pm 16 \ddagger$ & $0.40 \pm 0.11 t$ & $\star 1.1 \pm 0.2$ \\
\hline
\end{tabular}




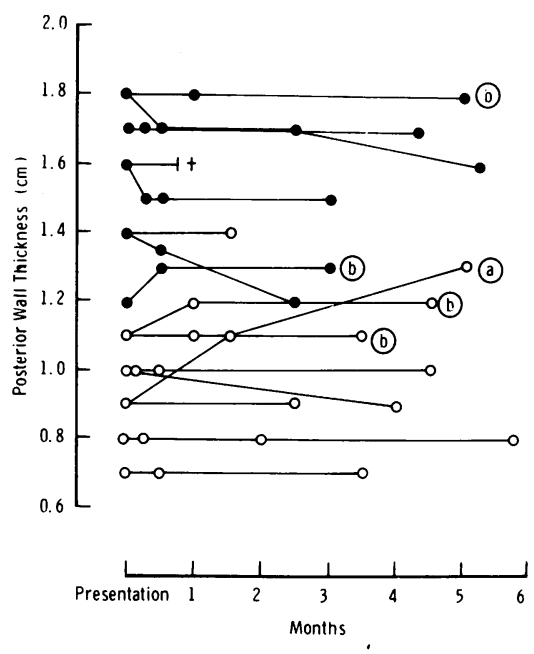

Fig. 5 Graph of left ventricular posterior wall thicknesses before and during treatment in malignant hypertension. previous history. previous history of hypertension. $\mathrm{O}---\mathrm{O}$ no

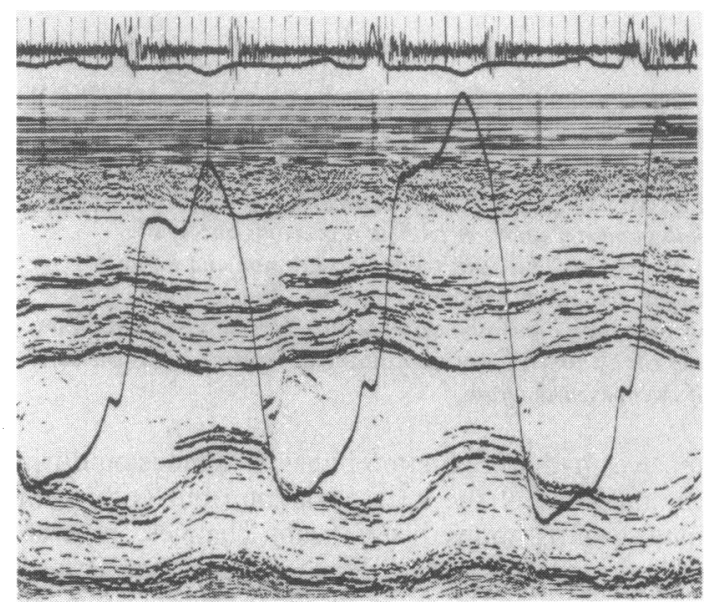

Fig. 7 Echocardiogram of patient with malignant hypertension (BP 230/146 mmHg) and previous hypertensive history. Note severe hypertrophy of posterior wall and septum, a tall apexcardiographic " $a$ " wave with normal cavity dimensions and ejection.

treatment patients without left ventricular hypertrophy normally showed no change, except patient (a) (Fig. 5 and 6) who had poor blood pressure control (196/126 mmHg after five months) and who developed hypertrophy (from 0.9 to $1.3 \mathrm{~cm}$ ). Cases with hypertrophy either showed no change or a tendency to a small reduction.

The left atrial/aortic root ratio was approximately unity in normotensives, but all hypertensives showed some increase and in untreated malignant hyperten-

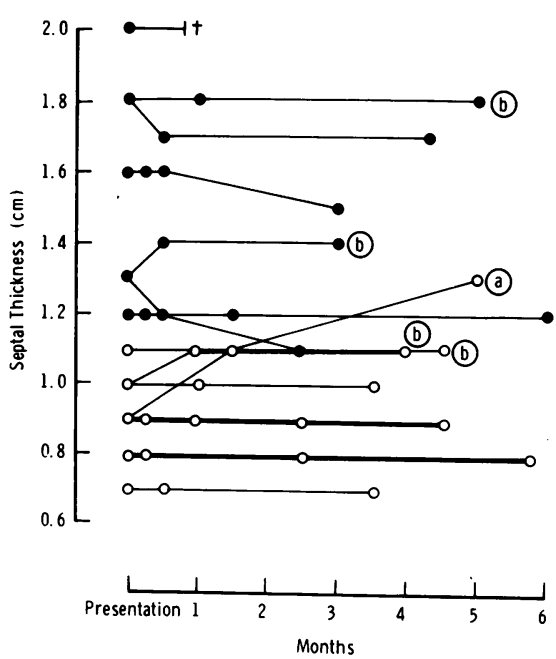

Fig. 6 Graph of ventricular septal thickness before and during treatment in malignant hypertension.

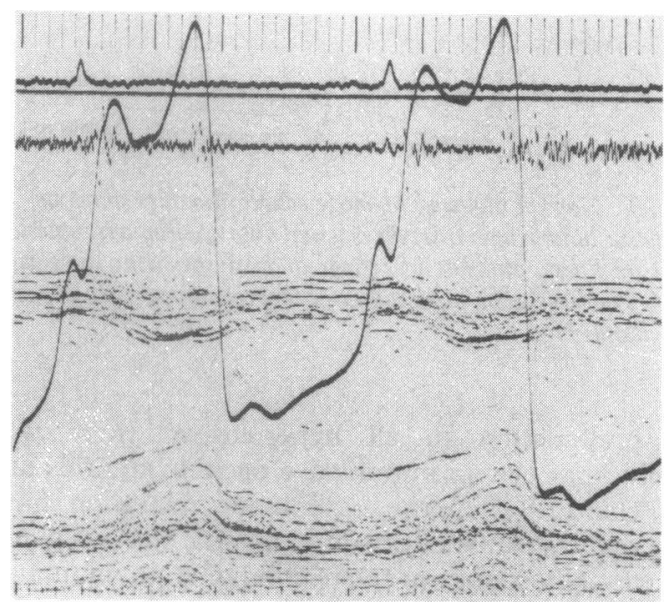

Fig. 8 Echocardiogram of patient with malignant hypertension (BP 245/163 mmHg) with no previous hypertensive history. Note absence of hypertrophy and raised $a / H$ ratio and normal cavity dimensions.

sives with a previous history the ratio was significantly greater than normal $(p<0.05)$. There were no significant changes with treatment.

\section{LEFT VENTRICULAR FUNCTION (Table 2, Fig. 9 and 10)}

\section{Time intervals}

The timing of $A_{2}$ was significantly early in the untreated patients, and returned to normal after treatment. 

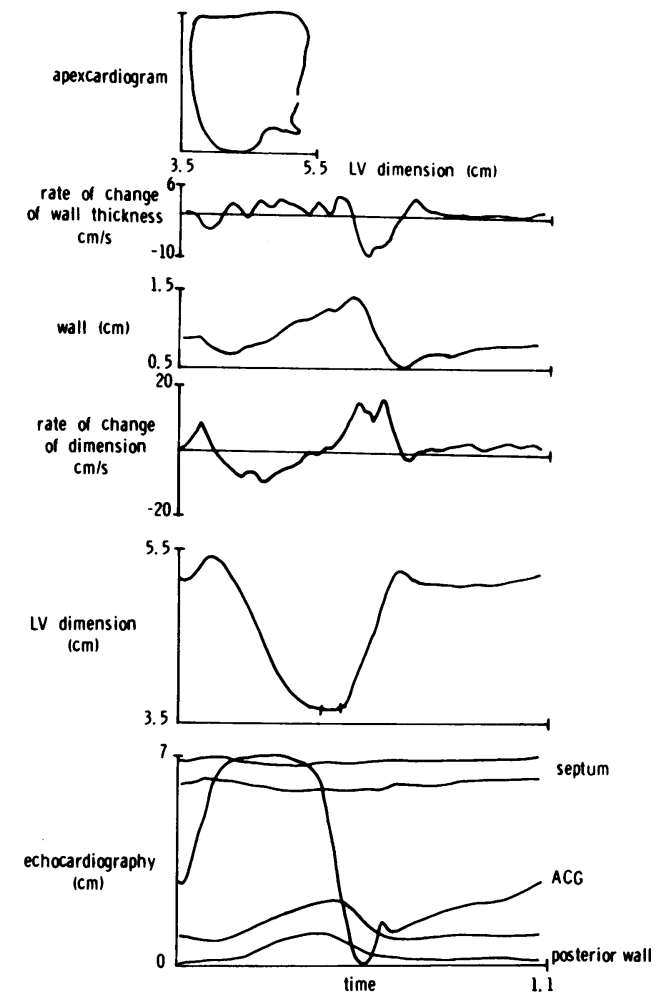

Fig. 9 Normal digitised M-mode echocardiogram showing (from the bottom upwards) the original data, continuous posterior wall thickness, and rate of change and an apex echo dimension loop. Two crosses on dimension trace represent aortic closure and mitral opening.

At presentation in all hypertensives there was significant delay in mitral valve opening and this did not change. Therefore, isovolumic relaxation time was reduced but remained outside the normal range because of a change in the relation of $A_{2}$ to minimum dimension and not because of a relative change in the timing of mitral valve opening.

\section{Left ventricular filling}

The peak rate of early diastolic filling was significantly reduced in all hypertensive groups and in some patients the duration of filling was prolonged. There were no significant changes with treatment even though the mean heart rate fell from 87 to $62 \mathrm{bpm}$ because of beta adrenergic blockade.

\section{Isovolumic relaxation and contraction}

All hypertensives showed an increase in cavity dimension before mitral valve opening, suggesting the presence of incoordinate relaxation and there were no significant changes during treatment. Benign hyper-

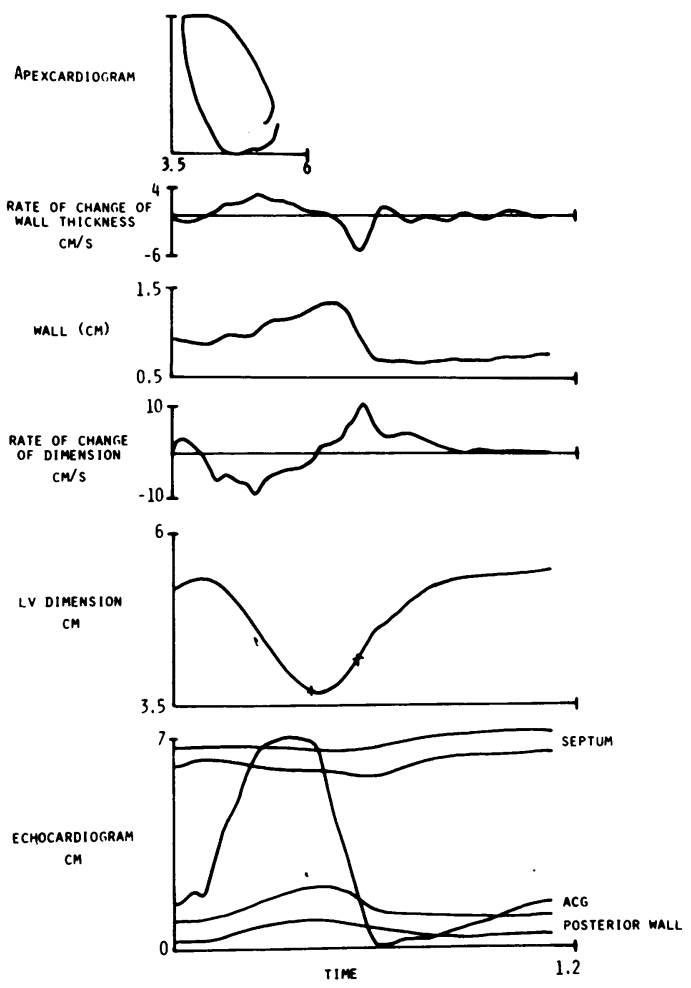

Fig. 10 Digitised $M$ mode echocardiogram of patient with malignant hypertension without a previous history of hypertension. This shows reduced peak rate and prolonged duration of cavity dimension increase, delayed mitral valve opening with dimension increase during isovolumic relaxation, and cavity dimension change during the upstroke and downstroke of the apexcardiogram.

tensives had no reduction in cavity dimension during the upstroke of the apexcardiogram but both malignant groups showed significant changes $(p<0.05)$, suggesting the presence of incoordinate contraction as well. After reduction of blood pressure, this was significantly reduced and was similar to that found in non-malignant hypertensive patients.

\section{Apexcardiogram}

Adequate traces were obtained in all but one hypertensive patient and in 10 of 12 normal subjects. Patients with benign hypertension had normal $\mathrm{a} / \mathrm{H}$ ratios, whereas those with malignant hypertension had significantly abnormal values $(p<0.01)$, suggesting raised left ventricular end-diastolic pressure. During treatment the mean values for both of these groups fell and in those without a previous history the change was significant $(p<0.05)$. Neither value, however, returned to normal; they remained significantly different from normal $(p<0.05)$. 


\section{Discussion}

We have shown that in patients presenting with malignant hypertension, the presence of a previous hypertensive history identifies two groups. ${ }^{67}$ Those with a known hypertensive history, either benign or malignant, tend to have ventricular hypertrophy and those presenting acutely without a previous history usually do not have hypertrophy. After a period of antihypertensive therapy, resolution of retinopathy and pulmonary oedema was noted, with no real changes in hypertrophy. Therefore, patients may have malignant phase hypertension and be successfully treated without developing ventricular hypertrophy.

Patients presenting with malignant hypertension form a heterogeneous group. One end of the spectrum was represented by a girl of 15 years with grade IV retinopathy with longstanding hypertension resulting from the Ask-Upmark kidney, who also had electrocardiographic and echocardiographic evidence of severe left ventricular hypertrophy without radiographic cardiomegaly or pulmonary oedema. At the other end was a middle-aged male smoker who presented for the first time with retinopathy, a normal electrocardiogram, no left ventricular hypertrophy, and $x$-ray evidence of pulmonary oedema. Presumably the first example resulted from a gradual increase in blood pressure and the second from a rapid rise, resulting in "left ventricular failure" not adaptation.

Left ventricular hypertrophy occurs in response to the peak systolic pressure in benign hypertension and is presumably an adaptive mechanism for maintaining relatively normal rate of contraction, peak systolic wall stress, and oxygen requirement. ${ }^{13}$ While the rate of development of cardiac hypertrophy is not known in man, it may occur in a few weeks after the application of a raised afterload in experimental animals. ${ }^{14}$ Good blood pressure reduction (below 145/ $100 \mathrm{mmHg}$ ) was obtained in $10(66 \%)$ of our patients and either no change in wall thickness or a trend toward a reduction was noted. Moderate blood pressure reduction (below $165 / 115 \mathrm{mmHg}$ ) resulted in no change in wall thickness and in one man who had no previous hypertensive history and poor blood pressure control an increase in wall and septal thickness was noted. In some patients with malignant hypertension either pressure rise is rapid and does not allow sufficient time for hypertrophy, or some other factor (such as ischaemia from arteriolitis) prevents its development. The usual response of a failing left ventricle, either from ischaemia or increasing afterload, is ventricular dilatation and reduced ejection with a raised end-diastolic pressure. This was not observed in malignant hypertensives, even with pulmonary oedema. Cavity dimensions and ejection remained relatively normal with raised end-diastolic pressure and abnormal filling relaxation, a similar situation to that found in hypertrophic cardiomyopathy. ${ }^{15}$ This may occur with excess catecholamine secretion, as we have described elsewhere in a woman with phaeochromocytoma. ${ }^{16}$

While left ventricular ejection remains apparently normal in malignant phase hypertension (presumably normal pump function is required to maintain the blood pressure), in response to grossly raised afterload, contraction becomes incoordinate and aortic valve closure occurs early. Because of the timing of $A_{2}$, isovolumic relaxation may be grossly prolonged. Delay in mitral valve opening was associated with outward wall motion reflecting incoordinate relaxation. Incoordinate contraction and relaxation are the result of abnormal myocardial properties or regional disturbances of function (such as in hypertrophic cardiomyopathy or ischaemic heart disease). ${ }^{11} 1517$ In addition, there was reduction in the peak rate and prolonged duration of the initial rapid phase of ventricular filling. These are also non-specific abnormalities occurring in all forms of hypertrophy such as hypertrophic cardiomyopathy, aortic stenosis, and hypertension. ${ }^{15}$ After reduction in blood pressure, the abnormalities of function return to levels similar to those found in benign hypertension. These abnormalities persisted even in the absence of hypertrophy and it must be assumed that they are caused by diffuse fibrosis disrupting myocardial relaxation.

Left atrial enlargement is sometimes found in benign hypertension, ${ }^{3}$ and in the malignant phase it was relatively common. While the abnormalities of atrial size were subtle, the apexcardiographic $\mathrm{a} / \mathrm{H}$ ratio was grossly raised. ${ }^{18}$ The highest values were found in malignant hypertensives without a previous history and those with radiological evidence of pulmonary oedema. After a reduction in blood pressure, the $\mathrm{a} / \mathrm{H}$ ratio fell significantly but remained abnormal. Its reversible nature suggests that the mechanism is similar to that found in the transiently ischaemic ventricle in coronary disease and that the reduction in afterload in our hypertensives improves myocardial perfusion. There was improvement in lateral ST segment and $T$ wave abnormalities in seven of 10 patients.

The high level of mortality in malignant hypertension is well known. Keith et al. ${ }^{19}$ in 1939 showed that the average survival time for untreated grade IV hypertensive retinopathy was 10.5 months, and as recently as 1952 to 1959 the five year mortality was $75 \%$. It was reduced to $66 \%$ only in the period 1960 to 1967.20-22 It is interesting to speculate on the cause of increased mortality in malignant hypertensives. While the absolute blood pressure levels are quantitatively greater than in benign hypertension, this cannot be 
the only factor. There may be a specific circulating humoral factor responsible for tissue damage, ${ }^{23}$ though immunological mechanisms may be important. ${ }^{21}$ We and others have shown, however, that cigarette smoking is strongly associated with the malignant phase and 13 of the 16 cases in this series were smokers. ${ }^{24}$ We suggest that in some patients with malignant hypertension blood pressure rises too rapidly for normal adaptive processes. In a 40 year follow-up of 1038 untreated hypertensives, approximately $1 \%$ were initially in the malignant phase, and no patient with benign hypertension developed malignant hypertension. ${ }^{25}$ Malignant hypertension may be a heterogeneous disorder, probably with different pathological mechanisms resulting in a similar clinical picture.

\section{References}

1 Pickering G. High blood pressure. 2nd ed. London: Churchill, 1968: 445-56.

2 Gudbrandsson T, Hansson L, Herlitz H, Andrén L. Malignant hypertension-improving prognosis in a rare disease. Acta Med Scand 1979; 206: 495-9.

3 Savage DD, Drayer JIM, Henry WL, et al. Echocardiographic assessment of cardiac anatomy and function in hypertensive subjects. Circulation 1979; 59: 623-32.

4 Dunn FG, Bastian B, Lawrie TDV, Lorimer AR. Effects of blood pressure control on left ventricular hypertrophy in patients with essential hypertension. Clin Sci 1980; 59: 441s-3s.

5 Cohen A, Hagan AD, Watkins J, et al. Clinical correlates in hypertensive patients with left ventricular hypertrophy diagnosed with echocardiography. Am $\mathcal{F}$ Cardiol 1981; 47: 335-41.

6 Shapiro LM, Mackinnon J, Beevers DG. Echocardiographic features of malignant hypertension. $\mathrm{Br} \mathrm{Heart} \mathcal{F}$ 1981; 46: 374-9.

7 Shapiro LM, Michalski AJ, Brown MJ, Grell GAC, Beevers DG. The heart in malignant hypertension. Clin Sci 1982; 62: 55p.

8 Bannan LT, Beevers DG. Emergency treatment of high blood pressure with oral atenolol. $\mathrm{Br} \mathrm{Med} \mathcal{F} 1981 ; 282$ : 1757-8.

9 Gibson DG, Brown D. Measurement of instantaneous left ventricular dimension and filling rate in man using echocardiography. Br Heart $\mathcal{F}$ 1973; 35: 1141-9.

10 Weissler AM, Harris WS, Schoenfeld CD. Systolic time intervals in heart failure in man. Circulation 1968; 37: 149-59.

11 Venco A, Gibson DG, Brown DJ. Relationship between apex cardiogram and changes in left ventricular pressure and dimension. Br Heart $\mathcal{F}$ 1977; 39: 117-25.

12 Voigt GC, Friesinger GC. The use of apexcardiography in the assessment of left ventricular diastolic pressure. Circulation 1970; 41: 1015-24.

13 Grossman W, Jones D, McLaurin LP. Wall stress and patterns of hypertrophy in the human left ventricle. $\mathcal{F}$ Clin Invest 1975; 56: 56-64.

14 Spann JF Jr, Mason DT, Zelis RF. The altered performance of the hypertrophied and failing heart. $A m \mathcal{F}$ Med Sci 1969; 258: 291-303.

15 Gibson DG, Traill TA, Hall RJC, Brown DJ. Echocardiographic features of secondary left ventricular hypertrophy. Br Heart $\mathcal{F}$ 1979; 41: 54-9.

16 Shapiro LM, Trethowan N, Singh SP. Normotensive cardiomyopathy and malignant hypertension in phaeochromocytoma. Postgrad Med F 1982; 58: 110-2.

17 Chen W, Gibson DG. Relationship of isovolumic relaxation to left ventricular wall movement in man. $\mathrm{Br}$ Heart $\mathcal{F}$ 1979; 42: 51-6.

18 Manolas J, Krayenbuehl HP, Rutishauser W. The use of apexcardiography to evaluate left ventricular diastolic compliance in human beings. Am $\mathcal{f}$ Cardiol 1979; 43: 939-45.

19 Keith NM, Wagener HP, Barker NS. Some different types of essential hypertension; their course and prognosis. Am F Med Sci 1939; 197: 332-43.

20 Breckenridge A, Dollery CT, Parry EHO. Prognosis of treated hypertension. Changes in life expectancy and causes of death between 1952 and 1967. Q J Med 1970; 39: 411-29.

21 Gudbrandsson T. Malignant hypertension. Acta Med Scand 1981; suppl 650: 1-62.

22 Gudbrandsson T, Snorrason SP. Severe arterial hypertension (grade III and IV). A clinical study on 117 hypertensive patients admitted to the department of medicine Landspitalinn, Reykjavik 1957-1971. Acta Med Scand 1976; suppl 602: 114-9.

23 Beilin LJ, Goldby FS, Mohring J. High arterial pressure versus humoral factors in the pathogenesis of the vascular lesions of malignant hypertension. Clin Sci Mol Med 1977; 52: 111-7.

24 Bloxham CA, Beevers DG, Walker JM. Malignant hypertension and cigarette smoking. $\operatorname{Br} \operatorname{Med} \mathcal{F} 1979$; i: 581-3.

25 Bechgaard PA. A 40 years' follow-up study of 1000 untreated hypertensive patients. Clin Sci Mol Med 1976; 51 (suppl 3): 673s-5s.

Requests for reprints to Dr L M Shapiro, Cardiology Department, Dudley Road Hospital, Birmingham B18 7QH. 